\title{
Deseo mimético y liberación en la inteligencia de las víctimas
}

Juan Sebastián Ballén Rodríguez

Universidad Cooperativa de Colombia 


\title{
Deseo mimético y liberación en la inteligencia de las víctimas*
}

Resumen: una de las intenciones que propone este trabajo es generar una reflexión filosófica a propósito de la definición social de la víctima. La hipótesis de esta investigación traza una apuesta hermenéutica sobre las maneras que tiene la filosofía del derecho de acercase a la condición epistémica de la víctima. Entre los criterios epistemológicos que permiten un acercamiento vivo, real y existencial al objeto-sujeto de investigación (la víctima), emanan de las fuentes tanto de la teoría del deseo mimético formulada por el francés René Girard (1923-2015) y que se nombrará en lo sucesivo 'fenomenología mimética', como de las tesis en materia de filosofía política que plantea el filósofo latinoamericano Enrique Dussel (1934).

Palabras clave: violencia, víctima, deseo de apropiación, liberación, fenomenología mimética.

\section{Mimetic desire and liberation in the victim's intelligence}

\begin{abstract}
: one of the intentions proposed by this work is to generate a philosophical reflection on the social definition of the victim. The hypothesis of this investigation is a hermeneutic approach on the ways that the philosophy of law has to reach the epistemic condition of the victim. By epistemic condition we understand the criteria of the possibility in which we can name the singularities of a social phenomenon, inevitably shown in the consciousness in an equivocal and elusive way. That is why, among the epistemological criteria that allows a real and existential approach to the object-subject of research, emanate from the sources of the mimetic theory of desire formulated by the thinker René Girard (1923-2015), and the thesis on political philosophy exposed by the Latin American philosopher Enrique Dussel (1934).
\end{abstract}

Keywords: violence, victim, desire of appropriation, liberation, mimetic phenomenology.

Fecha de recepción: 30 de septiembre de 2019

Fecha de aceptación: 30 de enero de 2020

Forma de citar (APA): Ballén-Rodríguez, J. (2020). Deseo mimético y liberación en la inteligencia de las víctimas. Revista Filosofía UIS 19(2), https://doi.org/10.18273/revfil.v19n2-2020010

Forma de citar (Harvard): Ballén-Rodríguez, J. (2020). Deseo mimético y liberación en la inteligencia de las víctimas. Revista Filosofía UIS 19(2), 181-205.

Juan Sebastián Ballén Rodríguez: colombiano. Magíster en Filosofía de la Pontificia Universidad Javeriana, Colombia.

ORCID iD: orcid.org/0000-0001-5214-3108

Correo electrónico: juansebastianballen@gmail.com

"Artículo de reflexión derivado de investigación.

Revista Filosofía UIS, vol. 19 n. ${ }^{\circ}$ 2, julio - diciembre 2020 


\section{Deseo mimético y liberación en la inteligencia de las víctimas ${ }^{1}$}

"Conviene saber que la guerra es común (a todas las cosas) y que la justicia es discordia y que todas las cosas sobrevienen por la discordia y la necesidad". Heráclito. Fragmento 53.

"Los misterios practicados entre los hombres son celebrados impíamente". Heráclito. Fragmento 14

“La relación con el mundo es la de tomar posesión y poseer, una relación en la que yo quiero convertir en mi posesión a todos y a todo, con inclusión de mí mismo".

Erich Fromm, ¿Ser o tener?

\section{De la psicología social a la teoría mimética}

La psicología para Erich Fromm es un saber social y humanista. Es social, pues, como continuador de la escuela neofreudiana, considera que la vida psíquica de las personas no nace individualmente. Es decir, contrario a lo que sostuvo Freud en el psicoanálisis, la psicología de los seres humanos no nace de la conflictividad interna que acaece en el sujeto cuando se manifiesta la pulsión erótica o tanática. En ese sentido, el movimiento que surge como crítica a los postulados del maestro explica que la hostilidad que experimenta la vida anímica de las personas surge en la interacción entre los individuos y los mecanismos sociales represores.

Lo anterior fue visualizado por la sociología de finales del siglo XIX, particularmente, en la perspectiva de Karl Marx o Max Weber. Existen variables sociales muy poderosas, como las relacionadas con el sistema de las relaciones económicas (capitalismo) o los sistemas normativos instaurados por las instituciones sociales (familia, escuela, iglesia y Estado) que modifican las conductas de los sujetos. La mayor de las veces para doblegar su voluntad, bien para enajenarlos en la forma económica o bien para mantenerlos controlados en la forma legal y jurídica de las instituciones (Manse, 1965).

${ }^{1}$ El siguiente texto es el resultado de la investigación La víctima, el campesino y el sacrificio en el marco de la transición política en Colombia: un estudio de caso por los territorios del Departamento del Meta (2019). Que se adelantó en la Facultad de Derecho de la Universidad Cooperativa de Colombia (Villavicencio). 
A juicio de Fromm, la vida psíquica se encuentra escindida entre el ser y el tener. Los conceptos de felicidad y bienestar social se hallan supeditados a las premisas sociológicas de las organizaciones industrializadas. Estas, en su afán de ánimo de lucro, prefiguran la finalidad moral y psicológica de los seres humanos en función del éxito personal sobre la base de valores industriales como la competitividad salvaje, el desmoronamiento moral de las relaciones interindividuales $y$, en general, el espíritu de la acumulación. Para Fromm, una visión ética y humanista de la psicología, además de identificar críticamente la falsa idea de felicidad que promueven las sociedades del mercado, tiene el compromiso moral y epistémico de privilegiar todas las formas espirituales y filosóficas que hacen posible una vida psíquica más sana, y donde se fomentan las habilidades del ser sobre el tener, como el amor desinteresado, el libre cultivo de la ciencia, la promoción del arte y la creatividad, etc. (Volpi, 2011).

La caracterología (la ciencia del carácter), disciplina psicológica de la que Fromm es fundador, parte de la idea ética según la cual los modos de ser de las personas son las virtudes (prudencia, fortaleza, justicia y templanza), y estas hacen posible una vida psíquica y social más armoniosa y pacífica. Los planteamientos frommnianos de una psicología en diálogo con la sociología, el psicoanálisis y la filosofía, conectan con la presente propuesta, pues está inspirada en un conjunto de tesis antropológicas y políticas que piensan la vida psíquica de las víctimas a partir del pensamiento religioso y la teoría política latinoamericana. Por otro lado, el contrapunto a la historia de las víctimas, idealmente, se encuentra en la formulación del deseo mimético propuesta por el francés René Girard (19232015), y en la filosofía de la liberación y el énfasis por la reivindicación de las víctimas que plantea, desde la filosofía política, el pensador latinoamericano Enrique Dussel (1934).

Los avances de Erich Fromm en materia de psicología social resultan reveladores para una comprensión humanista de la realidad social de las víctimas. Desde la teoría mimética es claro que el comportamiento social está precedido por la violencia de los deseos de apropiación, los cuales arrecian tan pronto se desata el conflicto entre el deseo individual con el de otra subjetividad que también apetece, situándose en potencia para comenzar un proceso interindividual de conflicto recíproco. A juicio del filósofo y jurista Paul Dubouchet (2018), entre las derivaciones económicas que se desencadenan de la teoría del deseo mimético, sobresale el comportamiento social de las personas en un escenario de transacción comercial en la que se privilegia la apropiación y el acaparamiento. El sistema económico capitalista no pretende generar la calma y la paz, sino más bien la violencia de la captura y la apropiación de bienes. Tal y como fue propuesto por 
la teoría del deseo mimético, toda la vida económica del capitalismo moderno y contemporáneo puede ser esclarecida a través de la mímesis de apropiación².

No se desconoce aquí que la narración de la víctima que atestigua el conflicto sociopolítico en Colombia está precedida por la mecánica mimética de la apropiación y la captura económica de bienes y personas humanas sin discriminación. La violencia indiferenciada totaliza el fenómeno de la violencia en Colombia. El conflicto colombiano es un episodio oscuro donde se reproduce la crisis trágica de un sacrificio humano sin redención, pues tanto buenos como malos, blancos y negros, azules y rojos se rinden por igual ante el poder abarcador de una violencia que no diferencia entre los roles sociales. La mismidad de la violencia abarca a todos por igual, instaurando a su paso la uniformidad del caos social.

Las conclusiones de la presente investigación están orientadas a través del recurso metodológico y filosófico de lo que denominamos como 'fenomenología mimética', porque privilegia en su análisis una descripción suficiente y compleja a la inteligencia de las víctimas. Esto se plantea si se tienen en cuenta los siguientes aspectos éticos, epistémicos y lingüísticos: primero, el valor moral y epistémico que reviste al lenguaje de los vulnerados se origina en una experiencia de

\footnotetext{
${ }^{2}$ Otras derivaciones que conectan el deseo mimético con las dinámicas sacrificiales que se practican en el capitalismo contemporáneo fueron explorados por Girard y sus diálogos con los teólogos de la liberación, en particular en la perspectiva de Franz Hinkelammert, para quien la ambivalencia del pensamiento mimético gravita en la distinción entre los autosacrificios y el don de sí. Lo primero está dado en aquellos sistemas sociales donde se produce la aceptación de los sacrificios, no siendo otra cosa más que la resignación de las víctimas ante la fatalidad de la ejecución por parte del verdugo. El sistema capitalista funciona bajo el modelo de los autosacrificios, que se implantan en América desde la conquista con el exterminio de los sistemas sacrificiales de los Aztecas, los Mayas y los Incas, para imponer las formas sacrificiales cristianas, que miméticamente caen en círculo vicioso de la repetición de la violencia. Por otra parte, del don de sí obedece a la entrega de la vida por cuenta de una razón justa (Assmann, 1991, p. 43). Para Benedito Ferraro el don de sí en el cristianismo sucede en el sacrificio que se realiza por justicia a los más vulnerables: en los tiempos de la teología de la liberación esta causa justa tiene que ver con una lucha social por la dignificación de la vida de los más pobres. Es así como la inmolación de Cristo obedeció a la causa de la justicia y la lucha por las víctimas. A contrapelo el sistema sacrificial por excelencia está representado por el dios-dinero. Se trata de una figura sacra e idolátrica que para Assmann: "[...] exige la sangre de los pobres, de los obreros, como ayer exigía la sangre de los indios y de los negros. Se cuenta que, en algunos lugares, los indios sacrificaban vírgenes a sus dioses. Pero los indios decían que los españoles sacrificaban millares de vidas, en las minas, al dios-oro. Hoy y aquí, en el fondo es la misma cosa la que continúa aconteciendo" (p. 45). Pensar los usos de la teoría mimética en América Latina es en cierta forma una opción moral y epistemológica por los pobres, tal y como lo declara Leonardo Boff siguiendo las huellas de la práctica sacrificial en el continente duran la época de la conquista: "Como decía un profeta maya-Quilambalucuando llegaron los conquistadores: los conquistadores aplastaron, mataron todas las flores para que solamente quedasen ellos. Esta es la lógica de la dominación: genera víctimas, mata las flores, tritura la cultura, destruye las relaciones sociales...es una inmensa cadena de víctimas" (Assmann, 1991, p. 47).
} 
violencia intensa o en el despliegue real de la mímesis por apropiación; segundo, la vivencia es el núcleo gnoseológico que explica la naturaleza equívoca, dramática y existencial de este tipo de racionalidad existencial y desiderativa; tercero, como ocurre en toda vivencia mimética, el relato o historia de vida descubre que la historia de un pueblo o comunidad se encuentra lastrada por la violencia, la cual busca salir al mundo, es decir, que el lenguaje y el símbolo son los recursos emulativos, referenciales e imaginarios que tiene el pensamiento de la víctimas para materializar una vivencia intransferible; cuarto, el relato de las víctimas tiene una vocación comunicativa, es decir, que busca empatizar con el interlocutor en procura de una comprensión intersubjetiva de una vivencia banal, desconocida absolutamente por uno de los integrantes del proceso comunicativo; y, cinco, la verdad, como la intención de objetividad que alcanza la inteligencia comunicativa de la víctima y que caracteriza a su lenguaje, es de naturaleza social e intersubjetiva.

En la inteligencia de las víctimas, la mímesis la integran tres violencias: económica porque existe una franca lucha fratricida por la posesión del objeto del deseo (la tierra); política porque en la disputa por el objeto del deseo y el otro que pretende arrebatarlo surge inevitablemente el antagonismo y la rivalidad ideológica, que continua el deseo mimético por apropiación con otros medios; y religiosa porque existe una práctica sacrificial donde opera una serie de prácticas rituales y simbólicas que redunda bien en la celebración de violencias profanas —es decir muertes despiadadas sin ningún contenido sacro—, o en actitudes y comportamientos de renuncia a los deseos de venganza que caracteriza a las víctimas que experimentan la conversión ${ }^{3}$. Estos tres momentos, actuando en

\footnotetext{
La conversión novelesca es semejante a la conversión religiosa de la que hablaron los primeros cristianos griegos. Y ello es así porque los escritores estudiados por Girard (Stendhal, Proust, Dostoievski, Cervantes) realmente encontraron en la escritura literaria una conversión en sus vidas. Fue la literatura la que hizo cambiar a estos escritores y puso en práctica en sus estéticas literarias el cambio de perspectiva. Como se estudia e Mentira romántica y verdad novelesca el fenómeno de la conversión literaria desde la perspectiva apocalíptica de la vida humana que narra Dostoievski en sus novelas. En efecto, la conversión literaria tiene que ver con el doble movimiento apocalíptico que atraviesa la humanidad y que va del infierno al paraíso o de la catástrofe a la revelación. El apocalipsis de la sociedad rusa para mediados del siglo XIX comienza por un relato sobre los malestares culturales del hombre moderno, representados en los dramas humanos que se cuentan en Memorias del subsuelo, Los hermanos Karamazov, Los endemoniados o en El eterno marido (Dubouchet, 2018, p. 115). ¿Cómo ocurre la revelación en Dostoievski? La muerte de los personajes y la conversión en otros seres menos miméticos y más espiritualizados es una muestra de la metanoia novelesca. Por ejemplo, en Los Hermanos Karamazov y bajo la voz de Iván Karamazov, Girard cuestiona el nihilismo intelectual en Rusia que tiende a desdibujar la figura de lo divino, sustituida por formas políticas de organización social como las que se plasma en los discursos socialistas y anarquistas. La radicalidad de estas ideologías por una reorganización de toda la humanidad actúa a modo de una tábula raza de cualquier otra experiencia distinta de lo social, conduciendo hacia la destrucción del mundo y la negación del pasado (Dubouchet, 2018, pp. 128-129). La revelación se muestra bajo el modo de una conciencia que descubre el doble vínculo en el que cae toda la humanidad al seguir la dinámica conflictiva del deseo mimético. La buena nueva es la otra cara de la revelación que busca salidas a la crisis que propicia la catástrofe política y moral de la violencia mimética.
} 
sinergia otorgan racionalidad al proceso de victimización que se origina en la violencia sacrificial.

La victimización no es la exaltación de la violencia infligida contra la víctima, sino la reivindicación de un proceso social de vulneración contra una personalidad que es objeto-sujeto del linchamiento social. Esta se manifiesta a través de un lenguaje que exterioriza el conflicto mimético y su salida (busca un modelo que sustituya la violencia sacrificial), y propende por una praxis, que de la mano de Dussel se ha denominado la dialéctica sustitución/liberación. Tanto en la teoría mimética, como en el proyecto de la filosofía de la liberación, es posible reconocer la voz y la historia a contrapelo de las víctimas, bajo la emergencia de una renovada racionalidad de los vencidos, que da cuenta tanto de la validez epistémica de su lenguaje (el relato), como de las implicaciones sociales de su acción en la historia (la acción política de las víctimas).

De este modo, distinguir que la racionalidad mimética, como el proceso de liberación que acaece el lenguaje de los vulnerados, es una manera de pensar una filosofía de las víctimas, se trata de un pensamiento que define la violencia y la conflictividad social como instancias propias del deseo humano. El mundo desiderativo de la apropiación hace parte de la episteme e incluso de la realidad psicosocial de la víctima. Salir del conflicto y de la lógica violenta de la acción recíproca es también una apuesta ética y cognitiva que desafía a las ciencias sociales e incluso a la filosofía del derecho.

La teoría del deseo mimético tiene las dos caras de Jano, pues muestra el origen de las discordias sociales y la reproducción de la acción recíproca en los sistemas de organización social (instituciones, estados y comunidades), como también las posibilidades para descubrir una salida a través de la mímesis por sustitución ${ }^{4}$, en donde el pensamiento simbólico y moral de las religiosas despliegan todo su potencial social y cognitivo en aras de procurar la armonización de las tensiones

\footnotetext{
${ }^{4}$ La teoría del chivo expiatorio es un hecho cultural que muestra el caos de la mímesis violenta que deviene en rito sacrificial o mímesis de sustitución. Este devenir es lo que conecta la antropología etnográfica y la etología con el pensamiento religioso. Es así como se distingue que el mecanismo mimético, si bien es una constante en el comportamiento social del hombre, no resulta suficiente para indagar las potencias metafísicas y religiosas de una mirada filosófica que explora una de las relaciones más cruciales en la historia del pensamiento occidental: la que puede mantener el animal simbólico con lo divino. Una de estas formas lógicas para pensar esta relación son las categorías de lo sagrado o mecanismo mimético por apropiación y sustitución. La mímesis es una manera de indagar filosóficamente por el origen de la cultura en relación directa con la violencia. El recurso mimético racionaliza el caos generado por un conflicto entre los miembros de una colectividad, hasta dimensionar las posibilidades para salir de ella a través del recurso de la mímesis de sustitución. La sustitución es el cambio que opera en la práctica sacrificial al intercambiarse la violencia mimética, por transacción con la inmolación de la víctima sagrada. El sacrificio como sustitución es un intercambio de trascendencia, en el sentido de que se trata de un trueque que asegura la no repetición del crimen y la inmunización social a través de una paz simbólica y momentánea.
} 
y las polaridades que originan la violencia de la apropiación y su consecuente caos social. A todas luces, estas aproximaciones filosóficas tienen por propósito contribuir en la comprensión de la realidad humana que por excelencia hace parte del objeto de estudio de la ética y el derecho, a saber: la justicia para las víctimas. En ese orden de ideas, esta propuesta investigativa se enmarca de un escenario reflexivo-filosófico.

En ese sentido, se expone inicialmente la teoría del deseo mimético mostrando sus bondades para abordar el estudio antropológico, estético y político de la condición humana que constituye a los vulnerados o víctimas. En este acápite, se hace énfasis en el potencial filosófico que otorga la teoría del deseo mimético al lenguaje y, particularmente, al que viaja en el relato literario. Una de las tesis que se barajan en este tópico del trabajo, sostiene que una manera de descubrir el potencial cognitivo de las víctimas se encuentra en su capacidad de contar historias, en otras palabras: en el deseo de narrar una serie de acontecimientos históricos relacionados con la violencia y el conflicto en el territorio, donde se involucran deseos de apropiación de objetos, modelos a seguir y sujetos deseantes, mientras se configura una suerte de racionalidad de los vencidos.

En un segundo momento, se aborda la lectura que propone el filósofo latinoamericano Enrique Dussel a la condición sociopolítica de las víctimas, prestando atención a su manera de situar la historia y la política de los vencidos desde una mirada muy particular de la religión, especialmente del cristianismo. Desde la propuesta dusseliana, se considera que es posible distinguir las potencias políticas de las víctimas, como sus pretensiones reales de reinventar una praxis social que haga justicia al fatalismo sacrificial que ha marcado la no-historia de los vencidos. En tercer lugar, se describe la fenomenología mimética, pensada como un recurso metodológico y filosófico para pensar el desenvolvimiento de la inteligencia de las víctimas.

De inspiración husserliana, la fenomenología permite dimensionar el talante epistémico y ético del lenguaje de los vulnerados. Se integra con la teoría mimética, básicamente porque la vivencia se encuentra atravesada por el fenómeno de la violencia, en donde se involucra la experiencia del deseo de apropiación, en conflicto con otros deseos semejantes (interindividualidad o intersubjetividad fenomenológica), donde se produce el conflicto con el otro.

En la conclusión, se hace mención del contexto sociohistórico que ha marcado el derrotero del conflicto social en los llanos orientales y se explica el porqué se necesita usar la teoría del deseo mimético para pensar la naturaleza de la violencia que precede todas las formas del caos social, como también su salida. En este asunto, se sostiene por tesis que la acción recíproca o la transacción violenta que ha orientado la lógica bélica por la Orinoquia colombiana se consuma en un sistema inequitativo sobre el acaparamiento de bienes (propiedad privada). 


\section{Deseo, imitación y violencia: la acción recíproca y su correlato mimético}

La filosofía de Rene Girard (2006) es una apuesta teórica que desarrolla dos tesis fundamentales y una idea matriz en los umbrales de los estudios literarios, la antropológica, la historia de las religiones, la mitología, el psicoanálisis, la filosofía política y de la religión. Estas dos ideas fuerza buscan estudiar la antropogénesis ${ }^{5}$ de la humanidad a partir de un principio constitutivo, que da cuenta de la dinámica conflictiva de las relaciones humanas: se trata del deseo.

Efectivamente, en la obra de Rene Girard se encuentra una referencia irrenunciable al carácter deseante de la subjetividad. De esta gran hipótesis se desprenden dos postulados básicos: uno, que desear es imitar, y dos, que imitar implica reproducir la violencia hasta que el movimiento caótico de la crisis mimética - la misma que despierta la reciprocidad violenta dada la confrontación de los deseos entre un yo y un tú- genere un mecanismo de expiación, usualmente atribuido a una víctima sacrificial que, bajo el tamiz del pensamiento simbólico, es ritualizada. El rito ejerce un efecto sobre la colectividad que se encuentra sumida en la barbarie y su ocultación. Se tiene, entonces, una teoría sumamente sencilla que triangula de manera interaccional las potencias humanas desiderativas, su trasmisión interindividual a través de la mimesis, como el mecanismo para la realización social de la paz: el chivo expiatorio.

En primer lugar, el deseo es una pasión humana, se desenvuelve a modo de un mecanismo que gravita entre las realizaciones y los fracasos, su naturaleza es oscilante y voluble. El deseo no acepta que el mundo o los otros se opongan a su consumación, y por ello lucha y no acepta los fracasos. Se trata de un devenir de la afectividad humana que bajo el comportamiento mimético encontrará el vehículo para una sublimación (a lo mejor, conducción u orientación en relación con el otro) ya sea positiva o negativa. De la mano de los grandes autores de la novela moderna, Girard descubre una 'visión fenomenológica' a propósito de 'la fábrica humana que son las relaciones interindividuales' dominadas la mayoría de las veces por conducciones y fuerzas intersubjetivas, que suelen caer en la conflictividad y el caos.

Una fenomenología que sigue de cerca el desenvolvimiento de los deseos humanos, trenzados en el conflicto cuando se entablan relaciones con mediadores lejanos, ocurre tal y como en los casos de Don Quijote y sus emulaciones al Amadís de Gaula o de Madame Bovary al fabular su vida en las historias sobre las doncellas en París. Asimismo, son los casos de Julián Sorel y los conflictos de ascenso social

${ }^{5}$ Con este término se quiere significar que una de las aventuras filosóficas que han identificado a Girard como un arqueólogo sobre los orígenes del hombre, tiene que ver con su manifiesta preocupación sobre el origen de la cultura. 
enfrentados con las relaciones amatorias furtivas vividas por el personaje con mujeres de la alta sociedad, o en los dramas del personaje de Memorias del subsuelo de Dostoievski, un burócrata que vive en medio de una sociedad que no lo comprende. La viva descripción que evoca Girard en el Quijote, pone de presente que en la literatura caballeresca es posible identificar las maneras que tiene el deseo de determinar su dirección. En el caso de Don Quijote la trayectoria del deseo va del personaje de caballería a la identificación de un modelo a seguir: el Amadís de Gaula. La imitación del modelo es un proceso emulativo, que pretende realizar en la propia persona la existencia de un alter (otro). Como ocurre para el cristiano, donde su existencia se cifra en la imitación de Cristo, lo mismo se da en la emulación que desea realizar con plena lucidez y admiración el caballero de la triste figura al seguir a su mediador, un personaje ejemplar dentro de las historias de caballería.

Los modelos literarios o las mediaciones encarnadas en personajes, es decir, los protagonistas y principales referentes de la imitación, como las figuras mitológicas, en donde las relaciones entre hombres y dioses juegan permanentemente con los modelos a imitar, se hallan permanentemente involucrados en el juego del engaño y el desengaño de lo deseos ${ }^{6}$. En esta hipótesis que conecta mímesis con elaboración ficcional de un modelo deseado, corresponde con la naturaleza narrativa e imaginaria que configura el relato de las víctimas.

La imitación es un proceso de creación de formas artísticas, tal y como fue considerado por la estética y la teoría literaria tradicional. La mímesis en un principio fue leída como un proceso servil, donde el artista reproducía la belleza en la naturaleza; con el paso del tiempo esta lectura fue perdiendo fuerza, hasta que se la ha definido en un sentido activo y productivo, gracias a la perspectiva de Genette, quien la significa bajo el apelativo de 'simulación' o construcción ficcional y simulacro que tiene el potencial de crear un mundo posible (Fusillo, 2012, pp. 28-30).

La mímesis al ser un simulacro de la realidad adviene como una invención de mundo. El simulacro da lugar a una segunda categoría estética que es el mythos o el relato donde se produce la composición de la trama. Como se verá más adelante, el paso de la mímesis simulacro al mythos relato, no solamente está

\footnotetext{
${ }^{6}$ Esta mirada fenomenológica al deseo se identifica a la luz del concepto de 'mímesis conflictiva' que Césareo Bandera usa para mostrar las relaciones entre las creaciones novelescas de Cervantes y Calderón. Sobre este concepto filosófico Girard comenta del siguiendo modo, en el prólogo a este trabajo: "[...] el deseo tiene en cuenta sus propios desengaños, pero no por ello se altera su mecanismo; esta conciencia de la desilusión no sirve para agravarlo, pues el deseo rechaza siempre y en cada momento la única solución que se le impone como necesaria y que consistiría en reconocer su fracaso esencial, en renunciar a sí mismo. Por no desesperar nunca bastante de la mediación, el deseo se adhiere de manera cada vez más estrecha al mediador, lanzándose a una servidumbre que empeora a cada paso" (Bandera, 1975, p. 10).
} 
dada bajo el imperativo de la creación estética en donde deben primar tramas "[...] bien representadas y bien estructuradas, coherentes y unitarias [...]" (Fusillo, 2012, p. 31), sino que ella misma pone de presente el nudo de la rivalidad y el antagonismo que se crea en la historia narrada, siendo el pre-texto para descubrir el origen de la violencia sagrada.

En La violencia y lo sagrado (2016a), particularmente en la revisión crítica que plantea Girard a la concepción freudiana del deseo, se contrapone la noción del rival a la de objeto del deseo. Para el francés, la dinámica del deseo desde la perspectiva mimética implica la existencia de un otro quien asume el rol del rival, presentándose como el verdadero obstáculo para la satisfacción del gozo individual. Al ser otro y su deseo el origen del deseo de apropiación, Girard descubre que el móvil de las acciones humanas más que estar contenido en la posesión del objeto y su satisfacción, se encuentra inducido de manera indirecta por un modelo que funge como mediador. El modelo o mediador es otro sujeto de deseo, que aparece bajo el rostro del rival dispuesto a oponerse y prolongar el juego entre una condición paciente y otra activa de las potencias desiderativas ${ }^{7}$. De ahí que el deseo mimético sea entendido como un deseo de interacción y donde se hace patente la dinámica de la relación social:

El rival desea el mismo objeto que el sujeto. Renunciar a la primacía del objeto y del sujeto para afirmar la del rival, sólo puede significar una cosa. La rivalidad no es el fruto de una convergencia accidental de los dos deseos sobre el mismo objeto. El sujeto desea el objeto porque el propio rival lo desea. Al desear tal o cual objeto, el rival lo señala como deseable ante el sujeto. El rival es el modelo del sujeto, no tanto en el plano superficial de las maneras de ser, de las ideas, etc., como en el plano más esencial del deseo.

(Girard, 2016a, p. 157)

Una manera de entender la dinámica de la figura modélica del deseo y su modo antagonista de mostrarse en el rival se encuentra en la literatura. Girard nos ofrece pistas hermenéuticas para abordar esta orientación. En el prólogo hecho por el francés al libro Mimesis Conflictiva. Ficción Literaria y Violencia de Cesáreo Bandera (1975) se esgrime que el

\footnotetext{
${ }^{7}$ No en todos los casos la relación mimética desata conflicto. En otros puede ocurrir que la reciprocidad violenta sea superada gracias a la distancia que genera una mediación no tan próxima. En efecto, para Girard el deseo cambia si la mediación con el modelo es interna o externa: en el primer caso la cercanía entre el sujeto y su mediación compromete los afectos en función de una imitación violenta que desata pasiones negativas, como lo son la envidia o el resentimiento. En otras situaciones, la mediación puede ser externa porque el modelo es lejano. Esta distancia omite el conflicto y crea una construcción onírica e idealizada del deseo mimético. Este segundo efecto es que le ocurre a Don Quijote y su fascinación por un personaje distante como lo fue el caballero Amadís de Gaula. Para una profundización sobre los ejemplos en la literatura moderna y el modo de aparición de la distinción entre la mediación interna y la externa puede revisarse Mentira romántica y verdad novelesca (1985).
} 
[...] deseo no se alimenta ni de las cualidades inherentes a su objeto ni de la espontaneidad del sujeto. Es decir, no se trata de esa relación lineal en la que siempre se había pensado: sujeto que desea-objeto deseado. La estructura de este deseo conlleva un tercer término que le sirve de guía y de modelo, el de mediador. (p. 9)

Los conflictos humanos (trágicos) que se desatan en la literatura no explicitan las fijaciones edípicas de los sujetos hacia el gozo o la negación que subyace a la posesión del objeto del deseo. Como se ha solido leer en la perspectiva freudiana o romántica, la literatura es el lugar para escenificar el drama de la patología psíquica o crisis interna que viven los seres humanos; un ejemplo de ello es el drama de Edipo. Los conflictos humanos que han sido entendidos por la literatura bien sean desde la caoticidad ínsita al género de la tragedia o la ironicidad y la burla que caracteriza al género de la comedia, tiene su origen en la 'rivalidad mimética' (Bandera, 1975). En otras palabras, las patologías psíquicas representadas por la mímesis literaria no ponen de presente el conflicto de la vida interior de los personajes de ficción. Al contrario, estas mismas enfermedades del corazón, obedecen fundamentalmente al deseo mimético que rivaliza con el otro. El origen de las patologías psíquicas se encuentra en las patologías sociales originadas por el deseo mimético ${ }^{8}$.

Finalmente, entre los juicios críticos a la teoría mimética ha sido usual la consideración de que su propuesta redunda en un reduccionismo de la vida social en la doble perspectiva de la violencia mimética y la práctica sacrificial. Esta suerte de panmimetismo (la mímesis en todo), en la que suele incurrir la teoría del deseo mimético, la convierte en una propuesta holística que podría ocultar otros procesos del mecanismo de las relaciones sociales, como los acaecidos en los episodios históricos de liberación o emancipación política de las colectividades. Una fuerza insurrecta que también puede recurrir a la no repetición de la violencia a través de una liberación creativa. Como podrá apreciarse en el estudio a la propuesta de Enrique Dussel, esas otras alternativas que buscan la liberación de los sujetos en la historia, son una forma de pensar la inteligencia de las víctimas en la perspectiva de una acción social renovadora, que trata de situarse en un plano distinto al que domina en los escenarios de la violencia mimética, la crisis sacrificial y la práctica de los linchamientos colectivos.

\footnotetext{
${ }^{8}$ De la mano del planteamiento girardiano y en su apuesta analítica por leer los procesos intersubjetivos de conflictividad social, se considera que el deseo mimético sí permite visualizar la realidad política y económica de las personas desde una patología social muy extendida como lo es el resentimiento, entendido como un odio hacia el otro que deviene en autodesprecio y frustración. Otras formas del deseo mimético son analizadas por el autor, de tal modo que la envidia es una variable estudiada en Shakespeare. Los fuegos de la envidia (2016b). Las pasiones negativas como la vanidad, el desdoblamiento o el crimen, son estudiadas por Girard al hilo de las novelas modernas en autores como Cervantes o Dostoievski, estudios que tienen lugar en Mentira romántica y verdad novelesca (1985).
} 


\section{Más allá de la mímesis por apropiación: el potencial ético- político de las víctimas}

Un fenómeno moral y social que arrecia en este proceso persecutorio y sacrificial es el que tiene que ver directamente con la invisibilización del otro. En otras palabras, la serie de hechos dolorosos que se enmarcan en un relato que atestigua la violencia y el conflicto, exterioriza un hecho sociológico palmario: las sociedades se encuentran determinadas por prácticas y ritos de violencia intensiva que semejan a las dinámicas de la religiosidad arcaica. No obstante, la violencia indiferenciada y sacrificial no solamente explica el comportamiento social de la religiosidad antigua, pues la historia de Occidente ha dado muestras de sustitución de la violencia intensiva a la organización social y el agenciamiento de paz colectiva.

Una de las notas distintivas de la vulneración de derechos en el siglo XX, tuvo relación directa con acontecimientos políticos que, de manera totalitaria, Ilevaron a cabo episodios de exterminio de masas, tal fue el caso del holocausto en Europa. En las dinámicas sociales del siglo XXI el blanco de las desapariciones no son las masas sino los colectivos, no las mayorías sino las minorías (MendozaÁlvarez, 2017, p. 32). La mímesis por apropiación es el mecanismo que explica la intencionalidad de control cultural y político que caracteriza a un pueblo que busca la dominación total de otro.

En este orden de ideas, cabría plantear la pregunta de ¿cómo superar un estado de barbarie generalizada que se asienta en el contexto de la violencia sacrificial y donde la inercia generalizada de los valores sucumbe por el poder que ejerce la mímesis por apropiación? En el lenguaje girardiano es claro que esta sustitución se produce a través de una renovada concepción religiosa de la vida. Esta promueve una lectura diferente a la lógica que explica la mecánica sacrificial en las sociedades arcaicas y modernas, la cual termina produciendo a su paso muertes indiferenciadas y crisis sacrificial.

La mímesis por sustitución pretende superar la violencia de la mímesis por apropiación, invirtiendo el movimiento reactivo de la violencia por otro totalmente distinto que fomenta la paz y la filosofía de la no violencia. Este sistema filosóficoreligioso de no violencia tiene correspondencias con una filosofía que ha sido practicada en Latinoamérica en la perspectiva de la filosofía de la liberación, divulgada por el pensador Enrique Dussel. A continuación, se observa cómo este giro de la teoría mimética a la filosofía de la liberación descubre las aristas políticas, históricas y teológicas para una filosofía de las víctimas.

Se podría argumentar que la reconstrucción de la historia de las víctimas toma distancia de la concepción usual que ha formulado la historia de las ideas políticas 
europeas. Occidente moderno, democrático y civilizador, asume la genética del Estado desde la reivindicación de derechos por parte del hombre blancoeuropeo y se sitúa después de 1789. Es decir, para la filosofía política moderna son sujetos reales los actores de la Revolución francesa quienes tomando la Bastilla reclamaron ante el desgaste de la ley feudal de la monarquía, fraternidad, igualdad y libertad. A juicio de Enrique Dussel (2007) esta lectura deja a un lado la otra historia moral y política de las víctimas, que se ubica históricamente con la irrupción de los modelos religiosos en Occidente. Para el filósofo latinoamericano, es con la aparición del cristianismo como se descubre una nueva conciencia de la libertad, la cual se traduce en protesta e inconformidad ante el trato de esclavo que recibió el hombre que emerge de los suburbios y las periferias que colindaron a las grandes civilizaciones de la Antigüedad.

Es la subjetividad dominada y conquistada la que carece de nombre y de memoria, la verdadera fuerza de trabajo que construyó la arquitectura política y urbana de la civilización en la Antigüedad. Las sociedades de hierro como la mesopotámica, la egipcia, la griega, la romana, la persa o la china cimentaron las conquistas culturales y políticas de sus mundos a partir de la dominación de sociedades esclavizadas. Para estas sociedades la máxima invención fue el hierro, el uso del caballo y el dominio del arado, elementos económicos y de desarrollo técnico que crearon a la subjetividad dominadora y victimaria.

A través del uso del caballo y la implementación de la herradura se explica el expansionismo territorial de estas sociedades, las que recorriendo grandes distancias subyugaron a los campesinos de las Ilanuras descubiertas. La reacción crítica al mundo esclavista promovido por el cristianismo pone en entredicho la grandeza de las civilizaciones y explica en buena parte una nueva mirada al otro, valorando la intersubjetividad del campesino y del esclavo, reconocidas como las verdaderas subjetividades donde la libertad no es un privilegio sino una conquista, una lucha que quiere levantarse contra su señor y descubrirse libre.

Se trata de la secularización que trae consigo la cosmovisión religiosa del cristianismo, el principal recurso ideológico y crítico para una transformación política del hombre en la antigüedad. Para los contemporáneos, descubrir que la subjetividad política se encuentra en la perspectiva del otro y en su condición de oprimido, es una manera de reconstruir la historia de las víctimas a contrapelo de quienes siempre han narrado el progreso y la evolución de los procesos históricos. Puesto el ojo de la historia sobre las subjetividades vencedoras, una política desligada de la memoria del otro posiciona la estirpe del poder (las élites) y la aparición de las instituciones del sacrificio humano (los Estados), como los fundamentos de una historia política eurocéntrica, colonial y desarrollista.

Se aprecia que en la perspectiva religiosa se descubre un tipo de subjetividad en donde se reconoce la condición de víctima ante el poder opresor del 
victimario. Condición social que explica, entre otras cosas, el poder revolucionario de los excluidos. Hunde sus raíces no en el poder militar o en la capacidad de dominación física para doblegar al otro, sino en el seguimiento a un modelo mítico que propende por la interlocución con los que siempre se han mantenido al margen y su voz se extingue en las profundidades de la pobreza. El seguimiento al modelo mítico propende por una revolución moral y política de las víctimas que descubre fundamentalmente:

La Alteridad del oprimido, de las víctimas, del pobre, la viuda y el huérfano, del extranjero, del excluido del demos o del fórum, de la carnalidad plena de necesidades (del comer, beber, vestirse, habitar...), clama desde su Exterioridad: imás allá de la fraternidad estoica nace la solidaridad con el Otro! El enemigo es trascendido. (Dussel, 2007, pp. 71-72)

Para Dussel, cuando la religión dirige su mensaje hacia la liberación del oprimido, propone un mito que cuestiona las viejas prácticas de la dominación. Una actitud filosófica ante estos mitos y narraciones distingue que en ellos es posible cambiar la manera de leer el papel del hombre en la historia. La filosofía no podría dejar a un lado los llamados a la liberación y a la reivindicación de derechos que claman los sujetos cuando se encuentran lastrados por las cadenas de la esclavitud. Para el filósofo:

Las rebeliones semitas (los movimientos mesiánicos del judaísmo, del cristianismo primitivo y de las primeras experiencias del islam), produjeron una profunda acción transformadora dentro del antiguo orden político esclavista [...], redefiniendo la intersubjetividad, subvirtiendo desde las víctimas aquellos sistemas del ejercicio del poder, creando nuevas instituciones, produciendo nuevo derecho, cambiando los principios normativos implícitos. (Dussel, 2007, p. 73)

El modelo que surge en medio de la dominación cultural y política de las grandes civilizaciones antiguas está encarnado en la presencia viva de un hombre que habla y denuncia la injustica. En el caso del cristianismo se trata de Jeshúa de Nazareth, un israelita crítico que conoce la ley judía y sus límites. Nace y se educa en medio de la imposición del dominio político y jurídico del Imperio romano, luego también conoce la ley del Cesar y sus límites. Es un hombre con una voluntad universal pues no considera que la redención este dada por una raza en especial (el linaje judío y su salvación o el linaje romano y su proyecto imperial y expansionista) ni tampoco en el seguimiento de una ley de membrecía ciudadana que permite gozar de algunos privilegios económicos (como ocurre con la ley de Roma). Este espíritu de universalidad hace parte de un mensaje revolucionario que rompe con las barreras del nacionalismo religioso o imperial. El descubrimiento del otro se produce en la predica de un hombre que enseña que la humanidad no está en la pertenencia a una raza o religión, tampoco en la filiación política y jurídica a un imperio. 
En la prédica de Jeshúa de Nazareth se encuentran los elementos universales y de liberación para una filosofía política de las víctimas. En sus enseñanzas, el mensaje de revolución se sitúa más allá de las fronteras culturales, morales y religiosas que mantiene a los pueblos en mutuo conflicto y violencia:

Por una parte, enseña a sus discípulos a evitar todo odio contra pretendidos enemigos desde una esperanza mesiánica universal, pero al mismo tiempo mina la pretensión teocrática del mesianismo político davídicos de ciertos grupos de su pueblo y abre el proyecto a todos los pueblos, más allá del horizonte del reino de Israel, incluyendo a todas las naciones (ethne) a los goim (así denominan los judíos a los no-judíos, a los paganos), en su nueva alianza intersubjetiva. Es un reino escatológico universal; un postulado ético-político. (Dussel, 2007, p. 71)

La originalidad de esta filosofía política no radica simplemente en la descripción de la pauperización de la víctima. La exterioridad radical en la cual se encuentra y vive el oprimido no es pretexto suficiente para la liberación moral y espiritual del pueblo de Israel. El verdadero descubrimiento de esta filosofía, que indaga por el origen moral y político de las víctimas, se encuentra en el otro. Es la alteridad ética la columna vertebral de una filosofía política de la liberación en la perspectiva de las víctimas ${ }^{9}$. La apuesta hermenéutica que propone Dussel a partir de las enseñanzas de Jeshúa, se inscribe en la pregunta que se encuentra en el evangelio: ¿quién es el prójimo? La parábola del buen samaritano es una historia que cuenta Jesús ante la observación de un legista, quien, para anunciar claramente lo que manda la ley para alcanzar la 'herencia de la vida eterna', de esta forma, sostiene casi de memoria que para llegar a la anhelada meta se debe amar a Dios con todo el corazón y las fuerzas y al prójimo 'como a ti mismo'.

La interrogación del hombre de leyes ante la pregunta ¿̇y quién es mi prójimo? es respondida con una historia en donde el seguimiento a la ley no resulta suficiente para entender el amor a Dios en el amor al prójimo. En el relato, un hombre de Jericó es asaltado, golpeado y dejado medio muerto sobre el camino. Por el trayecto, un sacerdote contempla la escena, da un rodeo y decide tomar otro camino. Un Levita, que también lo vio, dio un rodeo y cambia de ruta. Sin embargo, un samaritano que iba por el camino de la víctima mostró compasión, de modo tal que curo sus heridas y consoló su dolor y pena con aceite y vino. Dicho esto, Jesús indaga al legista: "¿Quién de estos tres te parece que fue prójimo del que cayó en manos de los salteadores?" (Lucas 10, 25-36). Evidentemente, ni el levita ni el sacerdote fueron ejemplos para entender el seguimiento a la ley de Dios, a pesar de ser sus conocedores más leales y reconocidos. Fue la práctica de

\footnotetext{
${ }^{9}$ En este sentido el comentario crítico de Daniel E. Guillot (1995) que dedica a la obra de Levinas Totalidad e infinito señala lo siguiente: “Dussel intentará ensamblar la noción de alteridad, y la ruptura de totalidad que implica, con la historia. Es necesario que el Otro entre en la historia y se concrete políticamente para que una ética de la liberación signifique algo más que el discurso para minorías de la filosofía académica" (p. 32).
} 
la misericordia la que cambió las coordenadas existentes de un ordenamiento social que invisibilizaba al otro.

Esta enseñanza es una muestra elocuente de que Jesús, en su mensaje, irrumpe críticamente ante las deficiencias de la ley judaica y levítica. Más allá del conocimiento de la norma se encuentra la ausencia de sensibilidad frente a la realidad del otro. La ley que manda amar a Dios sobre todas las cosas y al prójimo, como si se tratara del amor que se ha de procurar uno mismo, no se cumple. La judía como la levítica es una ley abstracta que omite el cuidado y la atención que merece el otro. Frente a la obra del samaritano tanto el Levita como el sacerdote quedan rezagados. Desde la acción del samaritano se descubre que el prójimo despierta un cambio en la dirección de la moral tradicional.

La axiología habitual ha solido invisibilizar el dolor y la vulnerabilidad del otro, por cuenta de una creencia de seguridad y prevención ante el peligro que normalmente mira para el otro lado. Se suele hacer rodeos ante el dolor del prójimo. Por lo que, la lección dejada por la historia del samaritano es un llamado a atender las heridas del otro en un cara a cara que desafía los referentes morales habituales. La ética de la alteridad exige una revolución interior de la moral tradicional. Una axiología atrapada en la ambigüedad de la cautela y el temor requiere de la trascendencia de una nueva acción, que irrumpa en el dominio de la totalidad de las creencias y lo establecido por la ley.

El conspicuo conocimiento de la norma no basta para comprender la inercia que mantiene a la víctima en un universo ético de exclusión e indiferencia. Desde la perspectiva racionalista y legalista de la cosmovisión ética y filosófica profana, la víctima se mantiene oscurecida por una perspectiva aristocrática y vertical de las relaciones interindividuales. En el universo lingüístico y hebraico del cristianismo y judaísmo la relación interpersonal se hace más radical que en el mundo el griego. Y ello es así porque para el Dussel (2007):

El concepto de plesíos (el cercano o póximo, prójimo) o de plesciazo (aproximarse o hacerse próximo) en griego no indica adecuadamente el reduplicativo hebreo de cara a cara (paním el paním). En este caso es la inmediatez empírica de dos rostros enfrentados, cara a cara, beso a beso, cuando se revela desde el sufrimiento de la víctima, en cuanto interpela a la responsabilidad política por el Otro y exige la superación del horizonte de la totalidad ('salirse del camino' establecido). (p. 74)

Para una teoría crítica de la realidad política de las víctimas, son dos las categorías que permiten identificar y superar un estado de dominación y barbarie. Dussel (2007) propone que, en primer lugar, se debe distinguir la existencia de un orden establecido, que denomina Totalidad, y que se identifica en el relato del samaritano en los comportamientos egoístas del sacerdote y el levita. El segundo 
momento corresponde a la trascendencia; la acción moral del samaritano estuvo marcada por la ética de la alteridad y esto hizo que la moral saliera del dominio de la totalidad, abriéndose al universo de la esperanza y la espiritualización de una realidad social subsumida en la apatía y la legitimación de la distinción social de castas superiores y otras inferiores.

La trascendencia puede superar el dominio de la totalización, así como la mímesis por apropiación es susceptible a conversión, esto es, al cambio, según la perspectiva de la mímesis por sustitución. En términos girardianos, se sostendría que la dinámica del deseo interno explica la fenomenología conflictiva de la víctima cuando esta se encuentra atrapada en los barrotes de la explotación totalizante, y que Dussel agencia el victimario en la pretensión dominadora y bélica que subyace a la racionalidad eurocéntrica del colonialismo epistémico y político. La liberación responde el movimiento inverso que suscita el deseo externo, ya que sitúa a la víctima en una perspectiva de trascendencia y acción liberadora en función de la conversión espiritual de su lucha, la cual justifica su batalla material contra un reparto de lo sensible, donde ha dominado históricamente la ley del más fuerte, es decir, la práctica de la injusticia en la égida de las castas privilegiadas que se embelesan en el poder. La mímesis por apropiación como la genealogía moral que da cuenta del derecho de guerra que agencia la casta más fuerte, se combinan no solo para oprimir a las víctimas, sino para hacerlas desaparecer de la historia.

Ahora bien, una mirada crítica a la teoría de la liberación en clave religiosa tendría que reconocer el valor social de las colectividades organizadas. A lo mejor, la excesiva confianza en las figuras morales más revolucionarias al interior del cristianismo — como ocurre con el seguimiento al modelo por excelencia: Jesús_ hace que se omita el hecho de que las acciones religiosas se encuentran enmarcadas en prácticas sociales más sistémicas, como las acaecidas en los rituales sacrificiales, acontecimientos sagrados que comprometen a todo el colectivo a participar de una celebración que renuncia a la reproducción de la violencia mimética.

\section{Sobre la fenomenología mimética}

La comprensión sobre la intensidad de la violencia por apropiación, como también de la tragedia social que ello desencadena, produce un sujeto histórico palmario y real: la víctima. Para escuchar la trayectoria de su dolor no basta con un informe judicial. La fuente de su drama está en su historia. Es su lenguaje o relato la mejor manera de plasmar la complejidad de la vida de las personas cuando se encuentran en medio del fuego cruzado, de la lucha de los intereses de partido que, al fin de cuentas, son intereses por el acaparamiento de la tierra. La expulsión de los campesinos y los indígenas de sus territorios es un lastre social que se produce luego del despojo organizado por el acaparador de turno. 
Para Husserl, la materialización inicial de una vivencia directa con las cosas mismas se encuentra en el lenguaje. Como lo comenta Jan Patočka, a propósito de la característica metodológica de la fenomenología husserliana, es el lenguaje la forma más expedita que tiene un ser humano para hacer presente algo a alguien que carece por completo de esta vivencia. En otras palabras, las víctimas comunican episodios de violencia hacia otros que no han tenido una vivencia semejante. Relatar la violencia a otro es comunicar la banalidad de un drama no vivido por el receptor del proceso comunicativo:

Uno de los pensamientos más importantes de Husserl-hilo conductor de sus reflexiones sobre el pensar humano y el conocimiento-es una evidencia sugerida por el lenguaje y sin el cual el lenguaje mismo no es posible, entendido el lenguaje no únicamente en el sentido de nuestra orientación en un mundo en el que las cosas están dadas inmediatamente sino también en un mundo que no aparece sólo como dado, un mundo que en su no presencia, o en tanto a las cosas están dadas inmediatamente sino también en un mundo que no aparece sólo como dado, un mundo que en su no presencia, o en tanto a las cosas que no están presentes, nosotros comprendemos de todas formas como presente. El lenguaje no es posible sino por el hecho de que somos capaces de pensar lo mismo, tengamos ante nosotros la cosa en su forma que se piensa lo mismo, tengamos ante nosotros la cosa en su forma y presencia concreta o nada en absoluto. Somos capaces de comunicar nuestra experiencia inmediata con quien no la tiene, y esto de forma que se piensa lo mismo, que aquel con quien nos comunicamos puede pensar lo mismo, dirigirse en la misma dirección. (Patočka, 2005 p. 12)

La dificultad de apresar en un concepto la riqueza de un testimonio es el límite de una filosofía de los derechos que preste atención al lenguaje del sujeto vulnerado. Por ello, se piensa que reproducir la historia de una voz, con el ánimo de ser lo más próximos al dolor del otro, es la oportunidad para escuchar y prestar oído al drama de una vida. ¿Qué es la fenomenología mimética? Uno de los medios idóneos para pensar la inteligencia de las víctimas tiene que ver con su materialización en el lenguaje, esto es, en el relato. Una narración que puede ser leída a través de una fenomenología mimética.

Así pues, se trata de una apuesta fenomenológica, ya que la identificación de un proceso cognitivo que busca la trascendencia, es decir, la elevación de la experiencia equívoca y relativa al dolor y la violencia, pretende alcanzar una construcción más o menos unitaria de su comprensión. Y finalmente, que mediante la equivocidad material que caracteriza a las situaciones y los personajes del relato, alcance la reducción eidética colectiva. Esto se comprueba cuando la víctima al mentar una historia de dolor fruto de una vivencia intensa de violencia, comunica su certeza sensible y esta puede ser comprendida por otro, ya que éste posee las potencias propias del pensamiento, la imaginación y la empatía. La 
fenomenología husserliana ha denominado este proceso cognitivo-intersubjetivo como corporeidad.

La dinámica fenomenológica de la corporeidad puede ser descrita de la siguiente manera. Los cuerpos humanos son algo más que meras realidades extensas y se conciben como cuerpos-yo, que vendrían a ser la representación de un sujeto cuerpo, que se proyecta en un nosotros cuerpo. La relación entre el yo- cuerpo con el nosotros-cuerpo es la correlación inicial de esta modalidad de la subjetividad. Para el filósofo alemán, la definición somática del cuerpo humano es al mismo tiempo una reconstrucción del mundo humanizado, ya no a partir el ego solitario (solipsismo), sino desde una comunidad de sujetos-yo (intersubjetividad) (Husserl, 1981).

Por 'construcción eidética colectiva' se entiende la comunicación intersubjetiva que resalta en el relato de una víctima de la violencia, cuya motivación psíquica y emocional es de raigambre moral y ontológica. Moral porque al relato lo atraviesa un juicio moral oscilante entre lo que es bueno y lo que es malo; y ontológica porque el ser sobre el cual emana el lenguaje se produce en medio de dolor originado por una relación social que privilegia la violencia como mecanismo expedito para la generación de la interacción social, en contextos donde dominan experiencias de conflicto y guerra fratricida — que sería la inercia de la materialidad o el imperio del no ser-.

En este sentido, la naturaleza fenoménica que caracteriza al relato de una víctima de la violencia en Colombia parte originariamente de una vivencia, que es profundamente mimética. Lo es porque presenta una intencionalidad desiderativa donde está involucrado el deseo de apropiación, el cual usualmente se ejerce como mecanismo de disputa en procura del dominio de la tierra. Se puede denominar también como deseo mimético interno, ya que es un deseo relacional donde afloran otros sujetos que desean lo mismo, y se baten en una batalla frontal y real alrededor del acaparamiento del objeto.

La mediación, que por excelencia son los mecanismos de la violencia mimética, en el relato de las víctimas es cambiante, ya que en su narración se muestran los diferentes recursos que tiene a la mano tanto la víctima como el victimario para satisfacer su deseo. Asimismo, se evidencia el seguimiento a un modelo, pues normalmente existe en estas historias un patrón de conducta sobre el cual se soporta el seguimiento a un referente mimético. La vivencia mimética es impresiva e intencional. Es impresiva porque el deseo de apropiación genera una marca sobre la piel. La adquisición del objeto de apropiación roza al sujeto y a otros sujetos involucrados en un deseo semejante. En ese orden de ideas, la guerra y la violencia social son elementos consustanciales al deseo mimético por apropiación. También es una vivencia intencional, porque la experiencia subjetiva 
del acaparamiento se encuentra volcada hacia la adquisición del objeto del deseo, en medio de una interacción social, donde adviene el otro como subjetividad extraña y enemiga a la realización del deseo propio.

Desde la teoría del deseo mimético se descubre que la vivencia del dolor se produce en el encuentro interindividual. No hay vivencias solipsistas en la fenomenología mimética, básicamente, porque el relato que caracteriza a la víctima surge fundamentalmente en la extrañeza que genera el advenimiento de otro deseo, encarnado en la vida de otro sujeto enemigo. Juntos desean lo mismo: acaparar la vida ajena encarnada en personas, cosas o en la mista tierra. En la semejanza y la emulación se producen las distintas prácticas de la crisis sacrificial.

En el lenguaje sacrificial existe toda una sintaxis que propende por una significación impresiva e intencional alrededor del linchamiento de una víctima. Girard (1982) evoca en El chivo expiatorio el uso que tuvo la palabra latina persecutio (persecución) y que para los cristianos Lactancio y Tertuliano tuvo curso en una suerte de sistema legal hecho para fabricar 'distorsiones persecutorias' (p. 261). Así mismo la expresión 'La víctima es un chivo expiatorio', hace parte de la representación persecutoria que construye de manera automática la mayoría de las sociedades cuando se asiste a una suerte de mecanismo sacrificial y que se encuentra a la palestra del juicio público. En el uso cotidiano que se hace de estas expresiones pervive el modelo de la 'causalidad mágico-persecutoria' y ello porque frente a la explicación de las causas naturales, en lugar de hacer uso de la ciencia, la humanidad ha preferido recurrir a "...las causas significativas bajo la relación social, y que admiten una intervención correctiva; en otras palabras, las víctimas" (Girad, 1982, p. 265).

\section{Conclusión: el llano en llamas y el deseo de apropiación}

Una continuación del dictum de Heráclito y que reza: "Conviene saber que la guerra es común (a todas las cosas) y que la justicia es discordia y que todas las cosas sobrevienen por la discordia y la necesidad" (Kirk, Raven y Schofield, 1999; Heráclito, Fragmento 53), es la concepción de la violencia como reciprocidad conflictiva. En esta dinámica el deseo es el factor psíquico y moral que motiva la acción de las personas. Los deseos son el potencial agonístico de los individuos cuando traban relaciones intersubjetivas.

La presencia del otro y su deseo advienen como un potencial antropológico cuya derivación intersubjetiva demarca las relaciones ontológicas con los otros, y es aviso de las implicaciones éticas y políticas de la acción humana cuya matriz es la violencia y el sacrificio. Una violencia practicada en sociedades lastradas por la guerra prolongada, situación que acontece fatalmente por más de 50 años 
en Colombia. El Ilano en Ilamas, título de la obra de Juan Rulfo, figura como un ejemplo modélico de los acontecimientos de violencia y conflicto que han marcado la historia del suroriente del país.

La Orinoquia colombiana es el centro de atención de este conflicto mimético. Según la Caracterización Región de la Orinoquía (2013), un territorio ubicada entre los países de Colombia y Venezuela y se define en su extensión por el impacto que genera la cuenca del río Orinoco sobre el ecosistema. Es una región extensa, pues comprende más de 34 millones de hectáreas las cuales beben de las aguas del río Orinoco, en ese sentido, es una cuenca que abarca la tercera parte del país.

Desde los tiempos de la conquista, la tierra llanera ha sido considerada como zona conflictiva. Emulando el título de la obra de Juan Rulfo, la historia de la Orinoquia es una repetición de El Llano en Ilamas. Y es así si tenemos presente que la región ha sido codiciada por conquistadores y colonos; por ejemplo, la llegada de Lope de Aguirre estuvo marcada por este destino, pues desafío la autoridad del rey de España al declararse dueño absoluto de la vasta selva que se extiende por la Amazonia hasta la Orinoquia.

Asimismo, la colonización de la Orinoquia ha alternado con procesos migratorios donde la violencia incita al despojo, saqueo y consecuente desplazamiento de los asentamientos indígenas y de los campesinos, lo que ha tenido por efecto un poblamiento disperso y caótico. Otra modalidad de la violencia mimética en el llano tiene que ver con la práctica colonial de la expropiación, la cual corre por cuenta del acaparamiento del minifundio, una explotación realizada por pequeños y grandes hacendados. Después de la colonización, esta fue la práctica social que se llevó a cabo en el llano bajo pretexto de la configuración republicana de un proyecto incipiente de nación.

Para la segunda mitad del siglo XIX, se redescubren los llanos orientales como una zona ideal para la edificación económica y política de Colombia. Como lo describe el antropólogo Augusto Gómez (1991) “[...] Desde el episodio del tabaco a mediados del siglo XIX, peones de las haciendas y parceleros cuyas propiedades se iban atomizando, iniciaron una larga historia de migraciones a veces de mano de obra estacional [...]" (p.4). Los desplazamientos y migraciones de las comunidades indígenas se enmarcan entonces en un contexto de violencia, palpable en una colonización que vio en la ganadería la continuación del despojo, pues:

[...] la prosperidad de la colonización de los llanos con base en la ganadería extensiva, ha restringido en el largo plazo el espacio vital de los grupos 


\begin{abstract}
indígenas cazadores recolectores, disminuyéndose drásticamente entre éstos las posibilidades de consumo de proteína animal (por el agotamiento de la fauna silvestre) viéndose así obligados a desaparecer como grupo y/o a reproducirse precariamente bajo otros sistemas adaptativos relacionados con la horticultura y el sedentarismo en los estrechos límites de las "Reservas" y "Resguardos" establecidos allí por el Estado. (Gómez, 1991, p. 6)
\end{abstract}

La colonización por parte de los españoles fue un fracaso. Los continuadores del proceso de colonización y reducción de pueblos indígenas correspondieron a las órdenes religiosas, la catequesis fue el recurso predilecto por parte de los evangelizadores. Fue un método de pacificación que iniciaba con dádivas y regalos, donde el aborigen caía de manera irremediable. Sus prácticas culturales tradicionales caracterizadas por su declarado politeísmo, y abierta poligamia junto a las borracheras fueron juzgadas con severidad por los religiosos. Como la pacificación a través del conocido intercambio se quedaba corta, las tareas misionales se convirtieron en auténticas expediciones de caza y captura de indígenas (Gómez, 1991). La colonización cristiana en aras de incorporar al indio bárbaro a la vida civilizada introduce la ganadería como forma económica socializadora, a pesar de las distintas circunstancias:

[...] que obstaculizaron la labor misionera y a pesar del fracaso de muchas reducciones, especialmente de aquellos intentos adelantados en el Orinoco, desde el siglo XVII y el trascurso del siglo XVIII, la acción misionera permitió la incorporación parcial de los Llanos a la vida colonial siendo la actividad comercial de ganados la base económica principal de esa incorporación. De los hatos y haciendas de misiones de los llanos se suministraban carnes y otros bienes a las haciendas y centros de población del altiplano cundiboyacense y entre tanto las haciendas-reducciones de los Llanos recibían herramientas, sal y otros productos del altiplano. (Gómez, 1991, pp. 20-21)

Como se ve, buena parte del conflicto y la violencia en el territorio llanero tiene su origen en la mímesis por apropiación que los historiadores, como los antropólogos y en general las ciencias sociales, han denominado indistintamente como 'proceso de conquista', 'colonización', 'pacificación' o recuperación del territorio según el lenguaje patriótico que caracterizó al periodo de la república en Colombia. La historia, y sus conflictos miméticos, continua en el suroriente colombiano, de tal modo que la guerra bipartidista de la primera mitad del siglo XX como la migración campesina a tierras llaneras, y la posterior conformación de las guerrillas liberales, lideradas por Dumar Aljure y Guadalupe Salcedo, son historias que repiten el mismo patrón de conducta mimética: apropiación, violencia y producción de víctimas. De modo semejante ocurre con el genocidio de la Unión patriótica (UP) y el conflicto territorial entre paramilitares y guerrilla que explica la violencia vivida en el llano para la segunda mitad del siglo XX. En 
estos momentos se asiste, luego de la firma de los acuerdos de paz en La Habana, al plan de muerte selectivo fraguado contra los líderes campesinos, que hasta el sol de hoy se mantiene en la completa impunidad ${ }^{10}$.

\section{Referencias}

Assmann, H. (1991). Sobre ídolos y sacrificios. René Girard con teólogos de la liberación. Editorial Departamento Ecuménico de Investigaciones.

Ballén, J. S. (2013). Desconstrucción, sofística y memoria en el holocausto étnico del Amazonas colombiano (1903-1910). Revista Signos, 34(2). 133-152.

Bandera, C. (1975). Mimesis Conflictiva. Ficción literaria y violencia en Cervantes y Calderón. Gredos.

De Manse, W.R. (1965). La psicologia social de Erich Fromm. Revista Mexicana de Sociología, 27(1). 219-240.

Dubouchet, P. (2018). La conversion Romanesque de René Girard. La littérature et le bien. L'harmattan.

Dussel, E. (2007). Política de la liberación. Historia mundial y crítica. Trotta.

Girard, R. (1982). El chivo expiatorio. Anagrama.

Girard, R. (1985). Mentira romántica y verdad novelesca. Anagrama.

Girard, R. (2016a). La violencia y lo sagrado. Anagrama.

Girard, R. (2016b). Shakespeare. Los fuegos de la envidia. Anagrama.

Girard, R., Antonello, P. y Castro Rocha, J. (2006). Los orígenes de la cultura. Trotta.

\footnotetext{
${ }^{10}$ A partir del informe especial Violaciones a los Derechos Humanos en tiempos de Paz (2019), realizado por el Instituto para el Desarrollo y la Paz (INDEPAZ), junto a la Cumbre Agraria, Campesina, Étnica y popular (CACEP) y la Coordinación Social y Política Marcha Patriótica, se afirma que después de la firma de los diálogos de paz en La Habana ocurrida en el año 2016, hasta el día 8 de septiembre del año 2019 se registra un escalofriante número de 770 líderes sociales asesinados en Colombia. La lógica sacrificial que ha marcado este genocidio político ha escalado a los extremos, identificándose 132 casos de para el año 2016, 208 en el año 2017, 282 en el año 2018 y 155 en el año 2019. Entre las víctimas se encuentran ex guerrilleros de FARC-EP, con un número de 151 asesinatos, dos para el año 2016, 38 en el año 2017, 76 para el año 2018 y 55 en el año 2019. La oleada de asesinatos ha llegado a los familiares de los excombatientes, siendo 35 las familias asesinadas, a pesar de estar en proceso de reincorporación. Desde la posesión del presidente Iván Duque hasta el día 8 de septiembre de 2019, 268 personas líderes sociales y defensores de los derechos humanos han sido asesinados en Colombia (Informe especial, 2019, p. 14).
} 
Gómez, A. (1991). Indios, colonos y conflictos. Una historia regional de los Llanos Orientales 1870-1970. Pontifica Universidad Javeriana. Instituto Colombiano de Antropología. Siglo XXI Editores.

Guillot, E, D. (1995). Totalidad e infinito. Ensayo sobre la exterioridad. Sígueme.

Husserl, E. (1981). La filosofía como ciencia estricta. Nova.

Instituto para el Desarrollo y la Paz (2019). Violaciones a los Derechos Humanos en tiempos de Paz. [Informe especial]. http://www.indepaz.org.co/wpcontent/uploads/2019/09/Informe-Violaciones-a-los-Derechos-Humanos-entiempos-de-Paz.-Septiembre-de-2019-18-09-19.pdf

Kirk, G. S., Raven, J. E., y Schofield, M. (1999). Los filósofos presocráticos. Historia, crítica con selección de textos. Gredos.

Mendoza-Álvarez, C., Jobim J. L. y Méndez-Gallardo, M. (2017). Mímesis e invisibilización social. Interindividualidad colectiva en América-Latina. En C. Mendoza-Álvarez (comp.). Universidad Iberoamericana.

Patočka, J. (2005). Introducción a la fenomenología. Herder.

Volpi, F. (2011). Enciclopedia de obras de filosofía A-G. Herder. 